\title{
INFORMATION AND ECONOMIC
}

\author{
ANALYSIS: A PERSPECTIVE*
}

\author{
Joseph E. Stiglitz
}

Ten years ago, I delivered a paper before this group with the title, 'Information and Economic Analysis.' I chose the title deliberately: I did not call the subject on which I was speaking the 'Economics of Information' because to do so would have been to suggest that my topic, like the economics of agriculture, or the economics of industry, or the economics of labour represented another branch of specialisation within economics. I wanted to suggest that informational considerations were, in fact, central to the analysis of a wide variety of phenomena, that they constituted a central part of the Foundations of Economic Analysis. At the time, though economists had long paid lip service to the importance of information, there was little formal literature. The last decade has seen a burgeoning of the literature. It has become to the late 70's and early 80 's what growth theory was to the early 60 's. And it has been greeted with some of the same scepticism. There seems to be a myriad of special cases and few general principles. The little examples are often contrasted unfavourably with the generality of general equilibrium theory. What have we learned? Have diminishing returns set in? Are there fruitful directions for future research, and if so, what are they? These are the questions which I wish to address here.

The work of the past decade has made, I think, a fundamental and lasting contribution to economic analysis. The contributions have been both negative and positive: we have learned that much of what we believed before is of only limited validity; that the traditional competitive equilibrium analysis, though having the superficial appearance of generality - in terms of superscripts and subscripts - is indeed not very general; the theory is not robust to slight alterations in the informational assumptions. It is but a special - and not very plausible - 'example' among the possible set of informational assumptions which can be employed to characterise an economy.

At the same time, the theory has been able to provide insights into phenomena about which the traditional model had nothing to say, or which seemed inconsistent or inexplicable within the competitive paradigm. It has provided some of the micro-foundations for macro-economics, it has provided the basis of a New Theory of the Firm, of a New New Welfare Economics, and of a theory of Economic Organisation (including a Comparison of Economic

\footnotetext{
* Frank W. Paish lecture. Condensed version, full version available from the author. I am grateful to Ian Galt for research assistance.

Financial support from the National Science Foundation is gratefully acknowledged.
} 
Systems which is of far more relevance than the misleading Lange-Lerner Taylor equivalency theorem).

Truth in advertising (itself a subject which can only be understood within an framework which focuses on imperfect information) requires, however, that I disclose some of what I shall not be able to do within this lecture. I have chosen to provide a general perspective, covering with broad strokes a vast area, leaving to the more technical surveys the task of filling in the details, specifying the specific assumptions under which the various assertions I make are valid. What I wish to show is how the "informational perspective" has altered both our views of how the economy functions and the approaches we take to the analysis of economic problems. But even with my broad strokes, there are important topics, including R \& D and rational expectations, which I will not be able to mention, let alone do justice to.

Finally, let me admit a failure: I would have liked to have been able to announce at this lecture one or two general principles, under which all or most of the relevant literature of the past decade could be subsumed. Those of you not actively engaged in Information Economics could then walk away from this lecture, knowing all you would ever need to know on the subject. There is no single new Law of Economics. There are a few themes, a few techniques of analysis, a few fundamental insights. More than that, a new perspective, a new way of approaching Economic Analysis has been provided, and it is this which I wish to convey to you today.

\section{THE FAILURE OF THE CONVENTIONAL \\ (PERFECT INFORMATION) PARADIGM}

Traditional economic analysis was predicated on three maxims. The first, due to Marshall, was that nature abhorred discontinuities. The second, due to Samuelson, was that nature abhorred non-convexities: not only could individual and firm behaviour be described as the solution to simple maximisation problems (in which an analysis of the second order conditions provides essential insights into the central comparative statics propositions), but the behaviour of the economy as a whole could be described as if it were the solution to some maximisation problem.

The third is the Law of Supply and Demand; it has played a central role in the traditional economist's tool kit. Indeed, there is a saying that you could teach a parrot to be an economist by simply teaching it to say. 'Supply must equal Demand'. It has played this central role in spite of ample evidence that there are circumstances where markets at least seem not to clear: massive unemployment of labour and extensive rationing of credit provide but two of the most important examples.

Recent work in the economics of information has cast doubt on all three maxims. The world is not convex; the behaviour of the economy cannot be described as if it were solving any (simple) maximisation problem; the law of demand and supply has been repealed. 'Unemployment and credit rationing 
are not phantasms. ${ }^{1}$ Indeed, in some circumstances, it may not even be possible to define demand independently of supply. ${ }^{2}$

Even the logic of the contention that individual and firm behaviour can be thought of as the solution to a maximisation problem has been questioned: for how is the individual to resolve the infinite regress of whether it is worthwhile to obtain information concerning whether it is worthwhile to obtain information... (See Winter (1964)).

Thus, Samuelson's contention that the analysis of maximisation behaviour provides the Foundations of Economics Analysis is at best a partial truth: it provides only one of the central building blocks.

Similarly the central insights of modern general equilibrium analysis - its stress on the interaction of markets and the role of prices in conveying information - though (at least partially) valid, are only a part of the story. In the standard competitive model, there is but a once and for all information problem; the economy does not confront the problem of repeatedly processing information (as it does in practice). What is meant by decentralisation is little more than a computer algorithm for the solution of a particularly complex problem. To ask, how information is processed and conveyed in the economy one must construct models in which information is continuously being collected and processed and in which decisions, based on that information, are continuously being made. Later in this lecture, I shall describe some ongoing work which is attempting to do just that. But even the work completed within the last decade has established that the interrelations among firms, individuals, and sectors are more complex than suggested by the traditional paradigm, that the notions of equilibrium embodied in that paradigm are special, and that prices are only one of the mechanisms by which information becomes conveyed in our economy.

\section{A Taxonomy of Models}

During the past decade, a large number of models examining economic behaviour in the presence of imperfect information have been constructed. Although I will not develop a complete taxonomy of that literature here, certain distinctions are worth noting: (a) while in models of adverse selection, there is imperfect information concerning the characteristics of what is being bought or sold in the market (labour, loans, or products), in moral hazard models there is imperfect information concerning the action which the individual undertakes; $(b)$ models may be either static or dynamic; in adverse selection models, the uninformed party (the employer, the insurance firm, etc.) may learn about the characteristics of the individual over time; in moral hazard models if the relationship (between buyer and seller, employee and employer, bank and borrower) is long term, the payments (e.g. to or from the insurance company or to or from the employer) will be made contingent upon

\footnotetext{
1 See Weiss and Stiglitz (1981).

2 See Grossman and Stiglitz (1976).
} 
observations made at earlier dates; $(c)$ in adverse selection models, information may be conveyed either by 'examination' (individuals search for the lowest price store) or by self-selection, on the basis of inferences made by observing the actions of the individual. The 'action' which conveys information may be 'quantity-related' - the amount of education, the amount of insurance, etc. - or price related - the willingness of an individual to buy insurance at a given premium, the willingness of a worker to work at a given wage, the willingness of a borrower to borrow at a given interest rate; $(d)$ In some cases, it is not the action of single individuals which conveys information, but action of groups of individuals. Thus, the set of prices in the market may convey information about the state of nature. In other cases, the information which is conveyed by a particular action is critically dependent on the behaviour of other individuals (the information conveyed by an individual applying for a job in a given labour market depends on the probability he has of obtaining the job, which depends on the number of other individuals who apply for the job; the information conveyed by an individual being in the 'used labour market' (individuals who have quit or been fired from some previous job) depends critically on the decisions of employees concerning quitting and employers concerning wage setting and firing); (e) Again, in the case of adverse selection models, it makes a difference whether the uninformed individuals move first (as in the insurance market, where the insurance firms are assumed not to know the characteristics of those applying for insurance, but offer a set of contracts to the market) or whether the informed individuals move first (individuals have to purchase a level of education before employers make job offers); $(f)$ while most models to date have been characterised by one-sided imperfect information (the employee knows the characteristics of the firm, but the employer does not know characteristics of the individual; while there is a moral hazard problem on the part of the seller of the commodity, there is none on the part of the buyer) in some recent research models with two-sided imperfect information are being investigated; $(g)$ while some models have investigated equilibrium in competitive markets, others have been concerned with monopolies or monopolistically competitive markets; $(h)$ though there are general principles which apply to all markets, there are some natural parameterisations, some simplifications which seem more appropriate in some markets, while others seem more appropriate in other markets. Thus, imperfect information (of all the kinds we have described above) has been explored in capital, labour, and product markets; in less developed countries as well as in developed economies.

\section{The Basic Propositions of Competitive Analysis}

Existence. When I addressed this group ten years ago, I noted that in models with adverse selection, competitive equilibrium might not exist, using what I thought at the time - and still think - was the natural definition of competitive equilibrium: in the context of insurance markets, that there existed a set of insurance contracts, all of which at least broke even, such that there did not exist another insurance contract which, if offered, would make a profit. Since 
then, there have been several attempts to find alternative equilibrium concepts, under which competitive equilibrium could be assured to exist. In my judgment, all of these have failed. There are, of course, assumptions (definitions) under which equilibrium can be shown to exist; but these all entail a small firm taking into account a variety of (often peculiarly restricted) reactions to his entry, which seems to me inconsistent with competitive analysis.

I gave a second example of non-existence: in capital markets in which prices convey information, I argued that if no one obtains any information there is an incentive to obtain information, but if anybody does obtain information, the price will perfectly reflect the information - so that the individual who expends resources to obtain the information is no better off than the individual who does not. It is clear that an equilibrium does not exist. This problem of existence, unlike the previous one, is merely an artifact of the assumption that there is no noise in the economy; if changes in the market price reflect changes other than just the information which has been purchased, an uninformed individual cannot infer the information perfectly from looking at the price. This result - the importance of noise in the existence of equilibrium - appears repeatedly in the economics of information. (See Grossman and Stiglitz, 1976; 1980.)

I want to mention two other examples of non-existence among many that have been discovered in the last decade, both of which are of serious (academic) concern.

The first of these results (Stiglitz, 1979, Salop and Stiglitz, 1982) is associated with a non-convexity that arises from the discrete nature of search: there is a fixed cost associated with obtaining an additional sample, of visiting an additional store. If firms can impose non-linear price schedules, then they can in general extract all the consumer surplus out of the marginal individual, the one whose consumer surplus from entering the market is lowest given that he has arrived at the store; but this means that, taking into account the cost of going to the store, the individual's return to entering the market is negative; hence he will not enter the market. But if the marginal individual does not enter the market, no one does: the excessive greed of the petty store owners has caused a collapse of the market. This problem can be remedied by the presence of noise: if there are heterogeneous products sold in the markets, individuals differ in their tastes, and firms cannot tell who likes which commodities, then market equilibrium is restored.

The second example of a non-existence result parallels the Rothschild and Stiglitz (1976) and Wilson (1977) analysis for adverse selection. Arnott and Stiglitz (1984), using the same definition of equilibrium employed by Rothschild and Stiglitz, show that when there is moral hazard and the quantity of insurance purchased by any individual is not observable equilibrium may not exist. They show that equilibrium, when it exists, can be characterised as the point on the price (premia per unit of benefits) consumption locus inside (or on) the feasibility set which maximises consumer welfare. But this contract can be broken by an insurance contract providing more complete insurance, when there is a point on the income consumption locus with the price corresponding 
to that of the candidate market equilibrium which lies interior to the feasibility set and generates a higher level of utility. But this contract itself is not an equilibrium.

What can we learn from this plethora of existence results? First, it is clear that the standard paradigm is not very robust: many of the non-existence results arise from only slight perturbations in one of the assumptions of the analysis. The Salop-Stiglitz non-existence in product markets arises if there are any costs to going to a store (no matter how small); the Rothschild-Stiglitz nonexistence result arises if there are only a few high risk individuals. Secondly there is no natural way of ruling out nonconvexities in the presence of imperfect information. Thirdly, some (but by no means all) of the problems arise from the fact that at least in many of the simplest models, an individual can obtain 'large' amounts of information from a single observation, so that they drastically revise their beliefs. The presence of noise eliminates many of these problems.

When, as in the Rothschild-Stiglitz model, we cannot restore equilibrium, either by the natural assumption of noise, or the use of a continuum of individuals, what are we to make of the non-existence of competitive equilibrium? What happens? The answer that I suggested a decade ago is still, I think, correct: markets are not perfectly competitive, though they may be monopolistically competitive. With perfect information and no nonconvexities, the postulates underlying perfect competition have a certain degree of plausibility, or should I say, at least internal consistency. The competitive paradigm is an artfully constructed structure: when one of the central pieces (the assumption of perfect information) is removed, the structure collapses. To construct a new paradigm several of the assumptions need to be replaced. This is the task to which I shall turn in the last part of this lecture.

\section{Adam Smith's Palsied Hand}

If there is one idea in economics that has attracted more attention than any other, it is Adam Smith's invisible hand: the notion that a competitive equilibrium would attain a Pareto efficient allocation. The results of the last decade have raised the possibility that Adam Smith's invisible hand may be something akin to the Emperor's New Clothes: The Invisible Hand may be invisible, because it simply is not there. But that, I think, underrates Smith's insight (and overrates the recent criticisms): I prefer to think of the Invisible Hand as being slightly palsied.

Information costs are no less real than production costs, and an evaluation of the efficiency of the economy must take these into account. (That is why I dislike the use of the term second best Pareto optimality or constrained Pareto optimality in analysing the optimality properties of economies with imperfect information: we do not use the term 'constrained' or second best optimality to refer to economies in which inputs are required to obtain outputs.) In traditional welfare analyses, we did not have to model the government very precisely: we established that no government, no matter how good, could do better than the private market. The results of the recent literature have established that that proposition is not correct: whenever there are information 
problems (whether of the adverse selection or moral hazard form) there are government interventions - taxes and subsidies levied on observable variables - which could make everyone better off.

These results can be looked at in several ways. One of the central results of traditional competitive analysis is the decentralisability of efficient resource allocations (without government taxes and subsidies). With imperfect information, there is a fundamental non-decentralisability theorem: efficient resource allocation cannot be efficiently decentralised without a whole set of subsidies and taxes. ${ }^{1}$ To put it in a slightly different way, there are instruments available to the government which are not available to individual firms: the government can (in principle) monitor all purchases of goods and services; it can tax or subsidised these purchases. A single firm might (at best) subsidise its customers' purchases of some other commodity (by providing a coupon) but it cannot tell whether the individual has resold the commodity to another individual and it cannot tax its customers' consumption of that commodity.

The presence of these externalities provides an incentive for markets to attempt to internalise the externality, by interlinking the markets. In some cases, such as LDC's, these interlinkages are a central part of the economy. But to the extent that interlinkages incorporate more and more of the economy the competitive nature of the economy becomes undermined.

What I would like to do now is to attempt to provide a heuristic argument for the Fundamental Non-Decentralisability Theorem. ${ }^{2}$

In the case of moral hazard, the argument is simple: the provision of insurance affects the extent of care that individuals take to avoid the insured against events occurring; the insurance company cannot monitor the actions of the individual. But his actions may be affected by relative prices (and by the availability of insurance policies covering this as well as other risks). By imposing subsidies on complements to the non-monitorable accident avoidance activities and taxes on substitutes, the government can encourage accident avoidance. By subsidising, for instance, fire extinguishers and smoke alarms, losses associated with fires may be reduced.

A similar argument holds for the case of adverse selection. The self-selection constraints are affected by relative prices; changing relative prices may affect, for instance, the cost differential between low ability and high ability individuals in obtaining increased education. By changing the price structure (through taxes and subsidies) in such a way as to make sorting easier the losses associated with the self-selection constraints (the excessive purchase of education, the under-purchase of insurance, etc.) can be reduced.

Whenever there is imperfect information, individuals (or other objects) which are in fact different will be grouped together; in an economy with rational expectations, the price of this heterogeneous melange of individuals will reflect their average 'quality.'

Some time ago (Stiglitz, 1975), I suggested that one could view imperfect

\footnotetext{
1 Even with taxes and subsidies, it may not be possible to decentralise competitively, because of important non-convexities, to which we have already alluded.

2 See Greenwald and Stiglitz (1984) for a general proof of this result, and Arnott and Stiglitz (1983) for a proof for the case of moral hazard as well as an analysis of the structure of corrective taxation.
} 
information like a tax (an ignorance tax). High ability individuals were taxed, while low ability individuals were subsidised. The distortions associated with this tax can be reduced by imposing other taxes, which encourage the supply of the taxed commodity (an increase in the supply of labour by high ability individuals) and a decrease in the supply of the subsidised commodity (a decrease in the supply of low ability workers).

Again, we need to ask ourselves, what are we to make of these results? What they show is how non-robust the Fundamental Theorem of Welfare Economics is. If one believes, as I do, that the problems of adverse selection and moral hazard are pervasive in the economy, then there is little ground for believing in the Pareto efficiency of the market economy. (The remarkable achievement of the Fundamental Theorem is to find that singular combination of assumptions for which Adam Smith's conjecture was correct.) Though recent analysis has identified the nature of the requisite interventions (the optimal corrective tax), and the empirical information is no greater (or less) than that entailed in the design of conventional optimal tax structures, I am not sanguine about government's ability to effect a welfare improvement. ${ }^{1}$ As I noted before, when we could establish the efficiency of the market equilibrium, we did not need to model the government precisely: no government, no matter how well organised, could effect a Pareto improvement. Now, our analysis has established that there are interventions which are feasible (within the information structure) which would effect a Pareto improvement. But why should we believe that such improvements would evolve out of our political processes?

\section{Repeal of the Law of Supply and Demand}

We noted in our discussion of the existence of equilibrium the critical problems posed by the definition of equilibrium. Traditional theory takes market clearing and the assumption that there is a single price associated with any commodity as part of the definition of competitive equilibrium. The new theory has had to look for more primitive, more fundamental notions of equilibrium, notions for which, under the traditional assumptions of perfect information, it can be proved that equilibrium is characterised by market clearing and unique prices: the law of supply and demand and the law of the single price are theorems (albeit trivial theorems) for the special example investigated by Arrow and Debreu and the subsequent literature. In the presence of imperfect information, under reasonable definitions, equilibrium is not characterised by demand equalling supply or by the law of single price.

The first result obtains whenever prices convey information about quality, that is, whenever the productivity of the labour force increases with the wage paid, or when the probability of default on a loan increases with the rate of interest charged, or when the quality of the product sold by a firm may be affected by the price charged. Quality may be affected either because of selection effects (the mix of applicants changes as the wage changes) or because

\footnotetext{
1 The information required for a welfare improvement may be even less.
} 
of incentive effects (the effort expended by an individual increases with the wage paid, or the riskiness of the projects undertaken by an investor - and hence the probability of default - increases with the rate of interest charged). ${ }^{1,2}$ In either case, the standard argument for why equilibrium should be characterised by market clearing no longer obtains. The standard arguments (it will be recalled) say that when supply exceeds demand, say for labour, the wage falls. An unemployed worker goes to a firm and offers to work for a wage less than it is currently paying its employees; but now the firm rejects this offer, since it believes that were it to hire this worker his productivity would be lower than that of current employees, lower enough that its total labour costs would actually increase. Similarly, if the demand for loans exceeds the supply, someone who does not obtain all the credit he would like goes to a bank and offers (in the traditional story) to pay a higher interest rate. But (in the new view) the bank believes that were it to lend at this higher interest rate, its expected returns would actually be lower.

In these situations, there exists a Walrasian equilibrium - a vector of wages and prices at which markets clear - but this is not the competitive equilibrium: there is nothing to stop a firm from raising its wage, when doing so increases its profits, or to stop a bank from lowering the interest rate it charges, when doing so increases its return.

\section{Repeal of the Law of One Price}

There have been three separate pieces of legislation repealing various parts of the Law of the Single Price. The first arose in the Rothschild-Stiglitz-Wilson analysis of competitive equilibrium with adverse selection: quantity variables (the amount of insurance purchased, the level of education, etc.) convey information; as a result, in market equilibrium the cost of insurance may not increase in proportion to the coverage or the interest charged may increase with the amount borrowed.

The second arises in the analysis of moral hazard, where quantity variables (the level of insurance purchased by an individual, the number of cigarettes he smokes, etc.) affect the individuals' accident avoidance activities or the effort he puts into a job. (See Arnott and Stiglitz 1984.)

The third arises when similar commodities are sold for different prices by different stores (or similar workers are paid different wages by different firms).

Though the facts that there are price distributions in the market, and that the existence of price distributions induces search, have long been recognised, the construction of equilibrium models of price distribution at first seemed a somewhat more difficult task: it must be optimal for firms to charge different prices or pay similar workers different wages. As it has turned out, there are

\footnotetext{
1 Thus, the first effect arises in adverse selection models, the second in moral hazard models.

2 There are other explanations for the dependence of quality on price. In the labour market, turnover may be affected by the wage. (Stiglitz, 1974). Akerlof (1984) has discussed sociological explanations of efficiency wages.
} 
now a plethora of such models. They are of four sorts: $(a)$ if firms differ, then the wage which it is optimal for them to pay similar workers may differ, or the price which it is optimal for them to charge may easily differ. Thus, in a model where workers may shirk, to avoid shirking, firms with higher monitoring costs will pay higher wages (see Stiglitz, 1974; Shapiro and Stiglitz, 1984); (b) if individuals differ, then price wage dispersions may be used as a discriminating device (See Salop (1977); Salop and Stiglitz (1977)); (c) if there is exogenous noise, (say affecting sub-markets) and arbitrage is costly, then equilibrium will be characterised by imperfect arbitrage across markets (Grossman and Stiglitz, 1976, 1980); (d) even if all individuals and all firms are identical, the profit function may have multiple peaks; the only equilibria may be characterised by price distributions. (See Stiglitz, 1974; Butters, 1977; and Salop and Stiglitz, 1982.) Thus, in the Salop and Stiglitz analysis, individuals can either purchase for current consumption only, or purchase in addition for future consumption, thus reducing future search costs. Under certain conditions, they show that there is no single price equilibrium: if all firms charged the same price, it would always pay a single firm to lower its price to induce customers that arrive at it to buy for future consumption. Notice in these models, the market creates noise; it is firms' attempt to take advantage of the fact that search is costly that leads to a wage or price dispersion.

Let me emphasise, in concluding this section, that I do not want to over-state my case: there may be situations, particular markets, in which information costs are low, and in which the traditional theory does apply: the Law of Supply and Demand and the Law of the Single Price remain valid. Our contention is only that there are many situations where information costs are significant, and where the nature of the market equilibrium is, as a result, significantly altered. To understand consumer and firm behaviour in these situations and to understand the consequences of various kinds of governmental intervention, requires an explicit analysis of how information affects the market equilibrium.

\section{TOWARDS THE CONSTRUCTION OF A NEW PARADIGM}

In the first part of this lecture, I spelled out the negative accomplishments of the recent work in the economics of information: How it has provided a fundamental criticism of the conventional competitive paradigm, showing that the existence, optimality, and characterisation results are not robust. I now want to discuss the more positive accomplishments: the insights it has provided into welfare economics, into the theory of the firm, into the nature of competition and the consequences of monopoly, into macro-economics, and finally into the theory of comparative economic systems.

\section{The New New Welfare Economics}

Shortly before and after the last World War, considerable attention was accorded to the New Welfare Economics. Its major accomplishment was that it dispensed with the interpersonal comparability of individuals (or at least 
attempted to distinguish among propositions which did and did not require interpersonal comparability). One resource allocation was 'better' than another if it Pareto dominated the other: some individuals were better off, and no one was worse off. Those who might be disadvantaged, for instance, by a new innovation were compensated by a lump sum transfer. The New Welfare Economics was predicated on the assumption that there was perfect information concerning individuals - e.g. it was known who was disadvantaged by the innovation. This assumption meant that lump sum transfers were feasible, which in turn had one important implication: the problems of economic efficiency and distribution could be separated. Every competitive equilibrium was Pareto efficient; if one did not like the distribution of welfare, one could simply engage in a set of lump sum redistributions. By engaging in different lump sum redistributions, one could trace out all Pareto efficient allocations.

The New New Welfare Economics is predicated on the assumption that the government does not have perfect information concerning different individuals; it cannot tell who is of high ability, who is of low ability, who is disadvantaged by some innovation, who is benefited by some public programme. It can elicit some information, but the processes by which this information is elicited affect resource allocations. Thus, the government cannot ask who is more able, who is less able, for individuals will not have an incentive to answer truthfully. The absence of this information means that lump sum redistributive taxes are in general not feasible; if the government wishes to redistribute income, it must do so through distortionary taxes. We can, however, characterise the set of Pareto efficient taxes. Assume that there are only two types of individuals in the economy, high ability and low ability. The government cannot, however, tell who is of which type; it cannot observe the leisure enjoyed by any individual, but can observe the income and consumption. While the New Welfare Economics characterised the utility possibilities schedules, the maximum level of utility that the less able could attain, given the level of utility of the more able, under the assumption that lump sum transfers were feasible, the New New Welfare Economics characterises the utility possibilities schedule under the assumption that lump sum transfers are not feasible. The government can impose a distortionary income (and commodity) tax structure, in which more able individuals are induced (by the choices which they face) to reveal who they are. But to induce individuals to reveal who they are (so that differential treatment is feasible) requires altering the set of choices facing individuals.

Whether moral hazard problems arise, and how they are best handled when they do arise, depends too on the distribution of wealth. Thus, the moral hazard problems associated with sharecropping arise partly from the fact that workers do not own the land upon which they work (and do not have the capital to buy it). Some of the moral hazard problems which arise in other aspects of the employment relation would be mitigated if individuals had the capital to post a bond. More generally a basic insight of the New New welfare economics is that whether the economy is or is not Pareto efficient may depend on the initial distribution of wealth (Shapiro and Stiglitz, 1984): the separation between equity and efficiency considerations is no longer generally valid. 


\section{The New Theory of the Firm}

There has long been a feeling among many economists that the conventional text model of the profit maximising firm, while it might have been appropriate for the simple owner-managed firms of the nineteenth century, did not provide an adequate description of modern industrial enterprises. Several alternative versions of managerial firms (March and Simon, Marris, Baumol, etc.) have been put forward. Economic theorists have looked askance at these theories: the market imposes discipline on managers to ensure that they engage in value maximising activities, both through shareholder voting and through the takeover mechanism. Managers who simply satisficed would be replaced by managers who maximised.

The New Theory of the Firm has placed the older managerial theory of the firm on a solid grounding: it has shown why neither the voting nor the take over mechanism will work to ensure value maximisation, in the presence of costly information. If obtaining information concerning whether the managers of the firm are managing the firms' assets efficiently is costly, then it does not pay any small shareholder to obtain that information: the efficient management of a firm is a public good. Moreover, as Grossman and Hart (1980) have pointed out, it does not pay any shareholder to sell his shares to anyone who has the promise of managing the firms resources more efficiently: he would prefer to have the other shareholders sell their shares, while he himself reaps the gain in market value resulting from the improved management.

Closer examination of managerial firms has uncovered a large number of practices which appear to be clearly inefficient, or at least not in the best interests of the shareholders. Although in most circumstances, economists do not have the information required to judge whether the managers are undertaking value maximising strategies, there are a few instances, mainly involving tax strategy, where we can assess management practices. The extensive use of accounting practices which do not minimise present discounted value of tax liabilities provides one set of examples. The distribution of returns to shareholders via dividends (rather than buying back shares) - the socalled Dividend Paradox - is another. The use of stock options as a method of compensating executives is a third.

Other examples of firms not maximising the value of their firm include the decision of managers of closed end mutual funds selling at a discount not to disband.

The separation between ownership and control has had, in turn, several interesting implications. First, it necessitates the design of incentive devices to help motivate managers to act in the interests of shareholders (Ross, 1973; Stiglitz, 1974). This affects not only the form of managerial compensation, but also the financial structure of the firm. The debt equity ratio affects the likelihood of a firm going bankrupt (and this, in turn affects managerial incentives, both with respect to effort and risk-taking). (Weiss and Stiglitz, 1981.)

Asymmetries of information affect the financial structure of the firm in other ways as well. While managers control the disposition of retained earnings, to 
get control of funds beyond those generated directly by the firm, they must persuade others to turn over their capital to them. Thus, the cost to managers of increasing equity by retained earnings and by issuing new shares are markedly different (and one sees remarkably little of the latter).

Indeed, while in the traditional theory, it is the shareholders who control the managers, in the new theory, banks may hold greater leverage over managers than shareholders; their threat to restrict credit is clearly more effective than a shareholders threat to vote for an alternative management team. (The role of credit restrictions as an incentive device is explored in Stiglitz and Weiss, 1983). ${ }^{1}$ It has long been noted that firms often seem to act in a risk averse manner. When managers are asked to evaluate projects, they are concerned with risk in the traditional use of that term, not just in the sense of the correlation of the return with the market. This behaviour seems hard to reconcile with the traditional theory of the firm: surely in the stock market, shareholders can sufficiently diversify themselves that they should be concerned only with the correlation with the return of the project with the market as a whole. Such risk averse behaviour is perfectly consistent with the new Theory of the Firm. Managers control the firm; their reward is dependent, in a significant way, on the performance of the firm. Asymmetries of information also mean that controlling shareholders often have a finite fraction of their wealth invested in the shares of a single firm, and that firms have limited access to the capital market (Stiglitz, 1982a).

\section{Perfect Capital Markets}

One of the more unpalatable assumptions of the conventional paradigm was that there were perfect capital markets. Individuals and firms are assumed to be able to borrow as much as they want at the prevailing rate of interest. Moreover, individuals should have widely diversified portfolios, and thus wish the firm to act in a risk neutral manner (paying attention only to the correlation of profits with the market). Capital markets are informationally efficient, with prices perfectly reflecting all the available information.

The perspective provided by information economics provides explanations for why these predictions of the conventional paradigm are incorrect and allows the construction of models of the capital market which seem more consistent with what is actually observed. Thus, we have already noted that in the presence of imperfect information, of either the adverse selection or moral hazard sort, there may be credit rationing; and that the issue of new equities may provide a signal which will depress the market value of outstanding shares and hence the effective marginal cost of issuing new equities may be very large. The cost of capital to a firm may rise as the original shareholders attempt to sell their shares, since doing so may be taken as a signal to the market. And even when it does not provide a signal, the debt equity ratio may affect managerial

1 Thus the Modigiliani-Miller theorem, which asserts the irrelevance of firms' financial structure, does not apply when there is imperfect information of the kind under consideration here. 
incentives, and thus, again, the cost of capital will be dependent on the debt equity ratio.

Grossman and Stiglitz $(1976,1980)$ have, further, pointed out that prices will not, in general, perfectly reflect the information which is available to the participants in the market. Only in the absence of noise will this be the case; and then, the market will only reflect free information: when prices perfectly reflect the information which is available, no one has any incentive to invest in information. There is an equilibrium level of disequilibrium in the market. But this 'natural' level of noise has no optimality properties.

\section{Theory of Competition}

The new information economics has lead to a revision of our views of the functions of competition: while it may perform the functions for which it is given credit in the traditional paradigm less effectively than that paradigm suggests, it may play other roles, not discussed in the traditional theory.

As noted in the earlier discussion, a central consequence of imperfect information is that markets will not be characterised by perfect competition, in the sense that this is normally defined; product markets are more aptly described by models of imperfect competition, where slight changes in prices do not result in firms losing all of their customers; they perceive themselves facing downward sloping demand schedules.

Indeed, the relationship between the number of firms and the competitivity of the market may appear to be quite different than in the traditional theory. Markets with a limited number of firms may have much more effective competition than markets with a large number of firms; in the former case, for instance, if any firm lowers its price, it will not induce anybody to search, while in markets with a limited number of firms, if a firm lowers its price, it may induce considerable search. As a result, perceived demand curves may appear to be more elastic with a limited number of firms. (See Stiglitz, 1983).

On the other hand, competition provides a basis of comparison; it provides information which can be used in the design of reward schedules which allows a firm to provide greater incentives with lower risk than it could in the absence of this information, and it allows the adjustment of the reward to changes in the environment. (This is referred to as the property of flexibility, Nalebuff and Stiglitz, 1983a). Markets have the property that, like contests and relative performance compensation schemes, they reward firms and individuals on the basis of how well they do relative to others; they thus have the property that the reward is automatically adjusted to the difficulty of the task. Moreover, the presence of competition allows the design of managerial reward structures which provide better incentives while allowing the manager to bear less risk. (See Nalebuff and Stiglitz, 1983b.)

Theory of Monopoly

The New Information Economics has affected not only our views on how 
competition works, but also our views on monopolies. The older theory focused on two cases: monopolists who could charge a single price to all customers, and perfectly discriminating monopolists. In the new theory, the central case is that of the partially discriminating monopolist, the monopolist who would like to charge those who enjoy a greater consumer surplus from his product a higher fee, but cannot identify who these individuals are. (The analogy between the problem facing the government, which would like to impose a higher tax on the individual with the greater ability, but does not know who those individuals are, and the problem facing the monopolist should be clear.) There is a whole set of devices which the monopolist can use to discriminate among different categories of buyers. The major distortions associated with monopoly arise from these discrimination devices. Among the discrimination devices are non-linear price schedules, producing products of different qualities, randomising prices (which discriminates among individuals with different search costs), tie in sales, and queues. The theory thus provides an explanation for many practices which seem inexplicable in the traditional theory.

It has also lead to a re-examination of the arguments for (and the analysis of the consequences of vertical integration. While the earlier literature simply assumed, for instance, that when two firms become integrated, their interests, which previously had been in conflict, now coincide, the new theory attempts to identify precisely in what way the set of available incentive structures might change by a change in ownership. (In the case of a merger, there is not even a change in ownership; what may be changed is the set of rules for the delegation of authority and decision making.) It asks, for instance, what can such a change accomplish that a set of contracts could not accomplish. These questions are closely related to the next set of topics which I wish to mention.

Finally, Salop (1979) has noted that the fact the price a monopolist charges conveys information about his costs can be used to develop a theory of limit pricing.

\section{The Theory of Economic Organisation}

The comparison of alternative economic systems has been a central concern of economics. In spite of its importance, the traditional theory gave us few insights. The Lange-Lerner Taylor Theorem suggested that market socialism and capitalism were equivalent. But neither the model of market socialism nor the model of modern capitalism on which this equivalence result was based remotely approximated the kinds of institutional structures found in the modern world. As I remarked earlier, the notions of decentralisation associated with neoclassical theory are more akin to a description of a computer algorithm - a description of how one might efficiently go about a complicated maximisation problem that one needs to solve once and for all - than of an institutional structure which is required to adapt and respond to a series of new and changing problems.

What I would like to do now is to describe briefly some work on which I am 
currently engaged, which has the promise of providing a more meaningful basis of a comparison of economic systems. Problems of information gathering, communication, and decision making are central in this view. Individuals have finite capacities to gather and process information, while communication of information between individuals is both costly and imperfect. Information gathering and decision making takes real time, and both because of positive discounting and because the environment is constantly changing (so that information quickly becomes obsolete) there is a return to making decisions quickly. The consequences of these simple observations is that how individuals are organised to gather information, how information is communicated, and how decisions are made is critical to the performance of the economic system. We refer to the pattern of organisation of individuals in an economic system as its architecture. ${ }^{1}$

To see more clearly what I have in mind, let me consider two simple architectures: polyarchy versus hierarchy. Assume the problem facing the organisation is choosing among a large number of projects, some of which have a positive expected return, some of which have a negative expected return. In the polyarchy, each individual has the discretion to accept or reject the project; projects which are rejected are 'thrown' back into the pool of available projects, and may be considered by another individual in the polyarchy. In contrast, in the hierarchy, projects are taken from the available pool only once. Those which are approved by the lower level in the hierarchy are passed onto the next, which re-examines them. (In our analysis, we assume that there is very limited communication among the levels of the hierarchy: only a binary message can be sent, indicating approval or disapproval.) It is easy to show that (under the assumption that the probability of approval of a given project by a given individual within each organisational structure is the same) while a hierarchy rejects more good projects, a polyarchy accepts more bad projects. Thus, the overall performance of the two organisations is partially dependent on the distribution of projects, the ratio of good projects to bad projects. But under the plausible assumption that there are more bad projects than good projects after all, it is easier to think up bad ideas than good ideas - polyarchy.performs better than hierarchy. (Hierarchies reject too many of the scarce 'good' projects.) This result holds when the acceptance levels are determined rationally, on the basis of the information which is implicit within the organisational design, in each system. It should also be noted that the fact that the probabilities of projects with different characteristics differ between the organisations will affect incentives for innovators; thus one would expect the two systems to differ in the set of projects among which they must choose.

The different forms of organisation correspond to different sequential decision making rules. For instance, in a hierarchy, the rule is 'if $A$ thinks well of the project, gather more information about it; if $A$ does not think well of the project, reject it.' In a polyarchy, the rule is, 'if $A$ thinks well of the project,

1 The work described in this section is being done jointly with R. K. Sah. See Sah and Stiglitz (1984). 
accept it; if $A$ does not think well of the project, throw it back into the pool and give someone else a chance to take a look at it.'

The results I have just described represent just the beginning of an ambitious research programme attempting to investigate the consequences of different organisational designs. What are the consequences of different spans of control, different numbers of layers within the heirarchy, the use of committees, operating under different rules, for decision making? One aspect, to which I wish to call attention, arises from the fact that when individuals differ (in their abilities to gather information, or to make decisions, or in their willingness to undertake risks) then an important problem arises in allocating, say, the more able individuals to different slots within the organisation. Not only may an individual's marginal productivity be higher in one position within the organisation than in another, but the performance of some organisational structures may be more sensitive to how individuals are assigned. In most organisations, of course, decisions about who holds what position next period are made by those within the organisation this period, according to certain rules. That is, organisations are self-perpetuating. And among the central decisions which individuals in an organisation must make are decisions about who should be their successors. These decisions, like decisions concerning which projects should be undertaken, are made subject to error. The kinds of errors which will arise, and the sensitivity of the performance of the organisation to these errors, are both functions of the organisational architecture. In current work, we are investigating the resulting relative performance of some simple organisational forms.

\section{Macro-economics}

Macro-economics provides perhaps the area in which the New Information Economics has had some of its greatest successes and failures. It has provided models which can explain unemployment, price and wage rigidities, and credit rationing. The question is, how plausible are these models? How plausible are their informational (and other) assumptions? And do they have implications which seem inconsistent with the facts?

The subject is too broad for me to do justice to it here, so let me focus my remarks on only one aspect, theories of unemployment. The set of theories that I find most attractive are the efficiency wage theories, which I discussed earlier, in which productivity depends on the wage paid. These yield competitive equilibria in which there may exist an excess supply of workers. Firms do not cut wages, in spite of the excess supply, because they know that doing so will reduce the productivity of their labour force (either through selection effects or incentive effects), reduce it enough so that firm profits are lowered. In some versions, such as those in which unemployment is used as a worker discipline device, the only equilibria entail unemployment (see Shapiro and Stiglitz (1984).) At full employment, workers have no incentive to work: the worst that happens to them is that they are fired, but with full employment they are immediately rehired at the same wage. (In their model there is no uncertainty 
about the characteristics of workers.) To induce workers not to shirk, firms raise their wages. As they all increase their wages, their demand for labour decreases and unemployment develops. It is the unemployment which provides the discipline that ensures that workers do not shirk.

Furthermore, the efficiency wage theories provide an explanation for why firms adjust their wages slowly, and for why firms that fail to adjust their wages may lose relatively little; they provide, in other words, an explanation of wage stickiness. (Given the wage paid by other firms, it does not pay any firm to reduce its wage by much, even though a coordinated wage reduction might be profitable. And given that the wage was chosen optimally, to maximise expected profits, the failure to adjust wages to a small change in the environment results in a loss which is of a second order of smallness.)

Having noted one of the sets of theories which I find attractive, let me mention one set of theories which I find unpersuasive: the implicit contact theory with asymmetric information. Numerous versions of these models have been investigated. For a brief survey, see Azariadis and Stiglitz (1983) and Hart (1983). These are one period models in which the employees are assumed not to know the state of nature, but employers do know. In order to ensure that the firm is honest in its revelation of the state, the employment, the choices of the firm must be restricted. As in the other problems of adverse selection which we have discussed, a distortion must be introduced: here, either the firm must be compelled to employ more labourers than it would like in good states, or fewer labourers in bad states. The latter may be interpreted as generating involuntary unemployment.

Let me explain some of the reasons why I find this theory unconvincing. First, under plausible assumptions concerning utility functions, it generates over-employment in good states, rather than under-employment in bad states. To generate unemployment for plausible assumptions concerning workers' utility functions requires that firms be risk averse (in marked contrast to traditional implicit contract theory where the function of the contract was to transfer risk from the workers to the firms). Its informational assumptions require both more and less information than seems plausibly available: to enforce these contracts, employment levels of the firm have to be observable, which means that the firm cannot contract out for labour services. (It also requires that the firm not be able to transfer some of its capital to another firm, or a subsidiary, thereby effectively avoiding the constraint on its employment.) On the other hand, there are variables, like industry sales, profits, unemployment rates, etc., which, though not perfect indicators of the state of nature, clearly convey information; if the central problem were that of the lack of information concerning the state of nature, surely this information should be employed much more extensively than it seems to be. Thirdly, these contracts are one period contracts, again, in marked contrast to traditional implicit contract theory which focused on long term contracts. While reputation may be an effective method of enforcing long term contracts, one period contracts can only be enforced if they are explicit; but few if any explicit contracts are of 
the form postulated by the theory. The threat of the withdrawal of current labour services may provide an effective enforcement device, but to the extent that this is the mechanism by which the contract is enforced, these theories become but a version of the efficiency wage contract theories. Moreover, these theories fail to explain why firms lay off workers, rather than engaging in work sharing. (The puzzle is particularly greater in the United States, where the lack of experience rating provides a strong incentive for rotating jobs when otherwise layoffs would extend over 26 weeks. The efficiency wage hypothesis does provide an explanation of lay-offs). Finally, they do not explain why other firms do not hire the workers who are layed off. (A theory of unemployment must explain both.)

The final theory of unemployment which I wish to mention is predicated on the assumption that the economy faces numerous disturbances which make it efficient for workers to shift from one firm to another, and that there are costs associated with this movement (specific training costs, moving costs, and search). Individuals are risk averse, and are less able to bear these risks than firms. On the other hand, if it is costly to monitor search, if individuals are guaranteed a wage, they will have no incentive to move, to seek out firms where their productivity is higher. (Indeed, in the traditional theory, this is precisely the function which wage differentials serve: to induce individuals to move from jobs where their productivity is low to jobs where their productivity is high.) The problem is a standard moral hazard problem, of the kind we discussed earlier. The solution is the usual compromise: partial insurance. Wages are not perfectly flexible, but they respond somewhat, to provide some incentive for workers to search. But more to our present point, the optimal contract entails lay-offs. (See Arnott et al. 1983.)

\section{Concluding Remarks}

The world-views which emerge from the alternative approaches presented in this paper are, I think, markedly different from those of the conventional theories which were prevalent until recently. The fact that both the assumptions of the analysis and the conclusions which it reaches seem more in accord with common sense seems a virtue, not a vice.

I concluded my lecture ten years ago by saying this new perspective would require a reassessment of our views of competition, equilibrium, and optimality. I went on to say,

\footnotetext{
'Although I know I have not gone very far in this lecture towards accomplishing this task, what I hope I have done is to communicate to you some of the perspective which the economics of information brings to these questions and to share with you some of the excitement that I feel as at last we begin to explore systematically an area, the potential importance of which has long been felt but whose full implications we are only now beginning to grasp.'
}

Most of what I said then is still true: We have made great progress, but new areas of research, new applications of this general perspective, have opened up 
as fast as results were obtained on long standing issues. The sense of excitement is still there: diminishing returns has not yet set in. Perhaps this too is simply a reflection of the Fundamental Non-concavity in the value of information.

\section{Princeton University and Hoover Institution, Stanford}

\section{REFERENCES}

Akerlof, George, (1984). 'Gift exchange and efficiency wage theory: four views'. American Economic Review Proceedings.

Arnott, R. and Hosios, A. and Stiglitz, J. (1983). 'Implicit contracts, labour mobility and unemployment'. mimeo. Princeton University. (revised version of a paper presented at NBER-NSF conference, Dec. 1980).

- and Stiglitz, Joseph E. (1984). 'Moral hazard and the existence of equilibrium in competitive insurance markets', forthcoming, Quarterly Journal of Economics.

Azariadis, C. and Stiglitz, J. E. (1983). 'Implicit contracts and fixed price equilibria', Quarterly Journal of Economics Supplement.

Butters, Gerald R. (1977). 'Equilibrium distribution of sales and advertising prices', Review of Economic Studies, (October), pp. 465-91.

Greenwald, Bruce and Stiglitz, Joseph E. (1984). 'Pecuniary and markets mediated externalities: towards a general theory of the welfare economics of economies with imperfect information and incomplete markets', NBER Working Paper 1304.

Grossman, S., and Hart, O. (1980). 'Take-over bids, The free rider problem and the theory of the corporation', Bell Journal of Economics, Vol. 11 (Spring), pp. 42-64.

-and Stiglitz, Joseph E. (1976). 'Information and competitive price systems', American Economic Review, Vol. 66, No. 2, (May), pp. 246-53.

_- and - (1980). 'On the impossibility of informationally efficient markets', American Economic Review, Vol. 70, No. 3, (June), pp. 393-408.

Hart, O. (1983). 'Optimal labour contracts under asymmetric information: an introduction'. Review of Economic Studies. Vol. 50. pp. 3-36.

Nalebuff, B. and Stiglitz, Joseph E. (1983a). 'Information competition and markets', American Economic Review, May, pp. 278-84.

- and - $(1983 \mathrm{~b})$, 'Prizes and incentives: towards a general theory of compensation and competition', Bell Journal, (Spring) Vol. 14, pp. 21-43.

Ross, S. (1973). 'The economic theory of agency: the principal's problem', American Econnomic Review, (May) pp. 134-9.

Rothschild, Michael, and Stiglitz, Joseph E. (1976). 'Equilibrium in competitive insurance markets: an essay on the economics of imperfect information', Quarterly Journal of Economics, November, Vol. 90 (4), pp. 629-49.

Sah, R. K. and Stiglitz, J. E. (1984). 'The architecture of economic systems: hierarches and polyarchies', mimeo. Princeton University.

Salop, Steven (1977). 'The noisy monopolist: imperfect information price dispersion and price discrimination', Review of Economic Studies, (October), pp. 393-406.

-(1979). 'A model of the natural rate of unemployment'. American Economic Review. Vol. 69. pp. 117-25.

_ and Stiglitz, Joseph E. (1977). 'Bargains and ripoffs: a model of monopolistically competitive price dispersions', Review of Economic Studies, Vol. 44, (October), pp. 493-510.

_ and - (1982). 'The theory of sales: a simple model of equilibrium price dispersion with identical agents', American Economic Review, December, pp. 1121-30.

Shapiro, C. and Stiglitz, Joseph E. (1984). 'Equilibrium unemployment as a worker discipline device', American Economic Review, (June), Vol. 73, no. 3, pp. 433-45.

Stiglitz, J. E. (1974). 'Incentives and risk sharing in sharecropping', Review of Economic Studies, (April), pp. $219-55$.

(1975). 'Information and economic analysis', in Current Economic Problems. J. M. Parkin and A. R. Nobay, (eds). Cambridge: Cambridge University Press, pp. 27-52. (Proceedings of the Association of University Teachers of Economics, Manchester, April, 1974.)

-(1979). 'Equilibrium in product markets with imperfect information', American Economic Review, Vol. 69, No. 2, (May), pp. 339-45.

(1982a), 'Information and the capital market', in Financial Economics: Essays in Honor of Paul Cootner, William F. Sharpe and Cathryn Cootner (eds.), Englewood Cliffs, New Jersey: Prentice Hall, pp. 11858. 
' $(1982 b)$. 'Ownership, control, and efficient markets: some paradoxes in the theory of capital markets', Economic Regulation: Essays in Honor of James R. Nelson. Kenneth D. Boyer and William C. Shepherd, (eds,), Ann Arbor, Michigan: Michigan State University Press, pp. 311-41.

(1983). 'Duopolies are more competitive than atomistic markets', Princeton University, mimeo, (October).

Weiss, A. and Stiglitz, Joseph E. (1981). 'Credit rationing in markets with imperfect information', American Economic Review, Vol. 71, No. 3, (June), pp. 393-410.

and-(1983). 'Incentive effects of terminations: applications to the credit and labor markets', American Economic Review, (December), Vol. 73, pp. 912-27.

Wilson, C. A. (1977). 'A model of insurance markets with incomplete information', Journal of Economic Theory, (December), Vol. 16(2), pp. 167-207.

Winter, C. (1964). 'Economic "natural selection" and the theory of the firm', Yale Economic Essays, Spring, pp. $224-72$. 
Copyright of Economic Journal is the property of Blackwell Publishing Limited and its content may not be copied or emailed to multiple sites or posted to a listserv without the copyright holder's express written permission. However, users may print, download, or email articles for individual use. 